\title{
OPEN Fe(II)-activated persulfate oxidation to degrade iopamidol in water: parameters optimization and degradation paths
}

\author{
Zijun Dong ${ }^{1,3}$, Guanhan Chen ${ }^{2,3}, \mathrm{Mu} \mathrm{Li}^{2}$, Feiyun Sun ${ }^{2 \varpi}$, Chengchun Jiang ${ }^{1} \&$ Bandna Bharti ${ }^{2}$
}

lodinated contrast media (ICM), which was widely used in medical imaging and was difficult to remove by conventional wastewater treatment methods, attained much attention due to its potential environmental impacts. Herein, iopamidol (IPM), one typical compound of ICM, was found to be rapidly degraded by ferrous activated persulfate oxidation (Fe(II)/PS) as compared with PS or Fe(II) alone. With a persulfate concentration of $1 \mathrm{mmol} \mathrm{L}^{-1}, \mathrm{n}(\mathrm{Fe}(\mathrm{II})) / \mathrm{n}(\mathrm{PS})$ of $1: 10$, and a pH of 3.0,78\% IPM was degraded within $60 \mathrm{~min}$, with a degradation rate of $0.1266 \mathrm{~min}^{-1}$. It was demonstrated that IPM degradation and deiodination were favored by a high temperature, while affected positively by acidic and neutral conditions. Radical quenching experiments and Electron Paramagnetic Resonace (EPR) spectra showed that the combined effects of $\mathrm{SO}_{4}^{-}$. and $\cdot \mathrm{OH}$ contributed dominantly to degrade IPM, while the $\cdot \mathrm{OH}$ played an essential role during the degradation reaction. Through the Discrete Fourier Transform quantum chemical calculation, the possible reaction pathways for the oxidation of IPM by -OH are as follows: IPM-TP651-TP667-TP541-TP557, IPM-TP651-TP525-TP557, IPM-TP705TP631-TP661, and IPM-TP705-TP735. The obtained results showed that IPM could be degraded effectively by $\mathrm{Fe}(\mathrm{II}) / \mathrm{PS}$ system, giving a promising technique for IPM removal from water.

Iodinated X-ray contrast media (ICM) has been widely used at medical centres and hospitals as an intravascular pharamaceutical to enhance the imaging of human organs, blood vessels and tissues ${ }^{1}$. Although ICM is non-toxic to human bodies, it is the source of total adsorbable organic iodine (AOI) in an aqueous environment that can act as a precursors to highly toxic iodinated disinfection by-products (I-DBPs) ${ }^{2}$. Creation of harmful I-DBPs is a progressing concern for the utilities of water. Generally, I-DBPs are considered to be more genotoxic and cytotoxic as comapared to their brominated and chlorinated additives ${ }^{3,4}$. ICM is frequently detected in aquatic systems, for instance, in China the total concentration of ICM was found to be between 102 to $252 \mathrm{ng} \mathrm{L}^{-1}$ in Huangpu River and 88.7 to $131 \mathrm{ng} \mathrm{L}^{-1}$ in Taihu Lake . Specifically, iopamidol (IPM), a typical ICM compound, was found in water resources with a concentration of about $1900 \mathrm{ng} \mathrm{L}^{-1}$ in Japan ${ }^{6}$. The growing IPM concentration has been traced in surface water, ground water, hospitals, treated wastewater effluents and domestic wastewater. As the IPM is one of the major contributor to I-DBPs formation ${ }^{7}$, and chlorination of $\mathrm{I}^{-}$could quickly form $\mathrm{HOI} / \mathrm{I}_{2}$, which was react with natural organic matters to form I-DBPs ${ }^{8}$. The odour and taste problems in drinking water were caused by I-DBPs.

Therfore, removal of IPM form the aquatic system have attained much attention. Various types of physical, chemical and biochemical techniques have been reported for the removal of IPM. From an economic and efficiency viewpoint and the biological recalcitrance of $\mathrm{IPM}^{9}$, researchers mainly focused on adopting physicochemical methods, rather than using single-stage physical, chemical or biochemical methods to degrade IPM in water. For example, Kong et al. studied the degradation of IPM by using UV/chlorine, by comparing with UV or chlorine alone $\mathrm{e}^{10}$, and they found that in contrast to chemical processes, biochemical methods have limited pollutants removal efficiency. For instance, it took over 20 days to achieve more than 95\% of IPM degradation by using anaerobic process ${ }^{11}$.

Recent reports on IPM removal and degradation by several treatment techniques were summarized in Table 1 . It was found that both $\mathrm{Fe}(\mathrm{VI})$ oxidation and UV/chlorine process had a relative high IPM degradation rate among these processes, although which were limited by their higher cost and potential production of DBPs. Interestingly,

${ }^{1}$ School of Civil and Environmental Engineering, Shenzhen Polytechnic, Shenzhen 518055, China. ${ }^{2}$ School of Civil and Environmental Engineering, Harbin Institute of Technology Shenzhen, Shenzhen 518055, China. ${ }^{3}$ These authors contributed equally: Zijun Dong and Guanhan Chen. ${ }^{\varpi}$ email: sun_fy@hit.edu.cn 


\begin{tabular}{|c|c|c|c|c|c|}
\hline Process & $\begin{array}{l}\text { IPM concentration } \\
(\mu \mathrm{M})\end{array}$ & Treatment condition parameters & IPM degradation efficiency (\%) & Rate Constant & Ref \\
\hline $\mathrm{CuO} / \mathrm{PMS}^{\mathrm{a}}$ system & 2.6 & $\begin{array}{l}\text { Temp }=25 \pm 2{ }^{\circ} \mathrm{C} ; \mathrm{pH}=7.0 \\
{[\mathrm{PMS}]=100.0 \mathrm{mg} \mathrm{L}^{-1}} \\
\mathrm{CuO} \text { dose }=0.2 \mathrm{~g} \mathrm{~L}^{-1}\end{array}$ & 100 (in $15 \mathrm{~min})$ & $0.218 \mathrm{~min}^{-1}$ & 14 \\
\hline $\mathrm{Fe}(\mathrm{VI})$ oxidation & 10 & $\begin{array}{l}\text { Temp }=25^{\circ} \mathrm{C} ; \mathrm{pH}=7.0 \\
{[\mathrm{Fe}(\mathrm{VI})]=0.5 \mathrm{mM}}\end{array}$ & $>80($ in $60 \mathrm{~min})$ & $55.8 \pm 3.5 \mathrm{M}^{-1} \mathrm{~s}^{-1}$ & 17 \\
\hline Chlorine & 5 & $\begin{array}{l}\mathrm{Temp}=25 \pm 1{ }^{\circ} \mathrm{C} ; \mathrm{pH}=7.0 \\
{\left[\mathrm{Cl}_{2}\right]=200 \mu \mathrm{M}}\end{array}$ & - & $(1.66 \pm 0.09) \times 10^{-3} \mathrm{M}^{-1} \mathrm{~s}^{-1}$ & 18 \\
\hline UV & 2 & Temp $=23 \pm 1{ }^{\circ} \mathrm{C} ; \mathrm{pH}=7.0$ & $<10($ in $30 \mathrm{~min})$ & $0.0336 \mathrm{~min}^{-1}$ & 10 \\
\hline UV/chlorine & 2 & $\begin{array}{l}\text { Temp }=23 \pm 1^{\circ} \mathrm{C} ; \mathrm{pH}=7.0 \\
\text { chlorine dosage }=200 \mu \mathrm{M} \\
\text { Light source: } 0.13 \mathrm{~mW} \mathrm{~cm}{ }^{-2}\end{array}$ & - & $0.3456 \mathrm{~min}^{-1}$ & 10 \\
\hline $\begin{array}{l}\text { Photocatalytic treatment processes using } \\
\mathrm{TiO}_{2}\end{array}$ & 25.7 & $\begin{array}{l}\mathrm{TiO}_{2} \text { Dosage }=1000 \mathrm{mg} \mathrm{L}^{-1} \\
\text { Light source: } 40 \mathrm{~W}, \lambda<360 \mathrm{~nm}\end{array}$ & $100($ in $16 \mathrm{~h})$ & - & 19 \\
\hline PS $/$ UV-A process & 2.6 & $\begin{array}{l}{[\mathrm{PS}]=0.5 \mathrm{mM} ; \mathrm{pH}=11 ; \text { Light source: }} \\
\text { UV-A, 7.6 W m}{ }^{-2}\end{array}$ & 100 (in $60 \mathrm{~min})$ & $0.1535 \pm 0.0037 \mathrm{~min}^{-1}$ & 16 \\
\hline PS/ZVAc system & 2.6 & $\mathrm{pH}=3 ; \mathrm{ZVA}=1 \mathrm{~g} / \mathrm{L} ; \mathrm{PS}=0.5 \mathrm{mM}$ & 55 (in $60 \mathrm{~min})$ & - & 13 \\
\hline $\mathrm{PS} / \mathrm{Fe}(\mathrm{III}) / \mathrm{GA}^{\mathrm{d}}$ system & 20 & $\begin{array}{l}{[\mathrm{PS}]=0.2 \mathrm{mM} ;[\mathrm{Fe}(\mathrm{III})]=10 \mu \mathrm{M}} \\
{[\mathrm{GA}]=10 \mu \mathrm{M} ; \mathrm{pH}=7.0 ; \mathrm{T}=25^{\circ} \mathrm{C}}\end{array}$ & 70 (in $60 \mathrm{~min})$ & $0.048 \mathrm{~min}^{-1}$ & 20 \\
\hline $\begin{array}{l}\text { ZnO-based materials and enzymes hybrid } \\
\text { systems }\end{array}$ & 12.9 & $\begin{array}{l}\text { Photocatalyst (SMA-Ce-ZnO-plus SBP) } \\
\text { dosage }=1 \mathrm{~g} \mathrm{~L}^{-1} \text {; Light source: } 40 \mathrm{w}, \\
\lambda<360 \mathrm{~nm} \text {; solution: } 5 \mathrm{~mL}, \mathrm{pH}=5.4\end{array}$ & 70 (in $24 \mathrm{~h})$ & $1.2 \times 10^{-3} \mathrm{~min}^{-1}$ & 15 \\
\hline Anaerobic transformation & 2.6 & $\begin{array}{l}\text { Oxygen-free Rhine water }(25 \mathrm{~mL}) \text { was } \\
\text { added to } 10 \mathrm{~g} \text { of anaerobic sediment } \\
\text { taken from a sulfate-reducing zone of a } \\
\text { polishing pond }\end{array}$ & $<5$ (in $60 \mathrm{~min})$ & - & 11 \\
\hline $\begin{array}{l}\text { Solar Photocatalytic Degradation with } \\
\text { Bi(0)-Doped Bismuth Oxyhalide Thin } \\
\text { Films }\end{array}$ & 0.13 & $\begin{array}{l}\text { Catalysis }=3 \% \mathrm{Bi} \text {-doped } \mathrm{BiOCl}_{0.875} \mathrm{Br}_{0.125} \\
\text { films } \\
\text { Light source: } 500 \mathrm{~W} \mathrm{~m}{ }^{-2} 280-950 \mathrm{~nm}\end{array}$ & 55 (in $60 \mathrm{~min})$ & - & 9 \\
\hline ZVA activated persulfate & 2.6 & $\begin{array}{l}\mathrm{ZVA}=1 \mathrm{~g} \mathrm{~L}^{-1} ; \mathrm{PS}=0.50 \mathrm{Mm} ; \mathrm{pH}=3 ; \\
\mathrm{T}=25^{\circ} \mathrm{C}\end{array}$ & $52($ in $60 \mathrm{~min})$ & - & 21 \\
\hline $\begin{array}{l}\text { Photocatalytic treatment with Ce-doped } \\
\mathrm{ZnO}\end{array}$ & 25.7 & $\begin{array}{l}{[\mathrm{Ce} \text {-doped } \mathrm{ZnO}]=1000 \mathrm{mg} / \mathrm{L} ; \lambda=290-} \\
400 \mathrm{~nm}\left(\text { Intensity }=24 \pm 1 \mathrm{~W} \cdot \mathrm{m}^{-2}\right) \\
\text { Temp }=26^{\circ} \mathrm{C}\end{array}$ & 100 (in $30 \mathrm{~min})$ & $0.12 \mathrm{~min}^{-1}$ & 22 \\
\hline $\begin{array}{l}\text { Electrochemical treatment } \\
\text { with } \mathrm{BDD}^{\mathrm{e}} \text { electrodes }\end{array}$ & $19.3-32.2$ & $\begin{array}{l}\mathrm{Na}_{2} \mathrm{SO}_{4}=2 \mathrm{mS} / \mathrm{cm} ; 0.31 \mathrm{~mA} / \mathrm{cm}^{2} \\
\mathrm{Temp}=20^{\circ} \mathrm{C}\end{array}$ & $>90($ in 16 h) & $1.2 \times 10^{-3} \mathrm{~min}^{-1}$ & 23 \\
\hline
\end{tabular}

Table 1. IPM main treatment process (2016-2018). a. PMS = Peroxymonosulfate. b. PS= Persulfate. c. $\mathrm{ZVA}=$ Zero-valent Aluminum. $\mathrm{d}$. GA = Gallic acid. e. $\mathrm{BDD}=$ Boron-doped diamond (BDD) electrodes.

persulfate (PS) or peroxymonosulfate (PMS) based processes have the high rate constant and removal rate to deal with IPM among these processes as shown in Table 1. PS was used to generate sulfate radicals $\left(\mathrm{SO}_{4}^{-}{ }^{-}\right)$by either homogeneous or heterogeneous advanced oxidation process (AOPs). Being relatively stable at a room temperature, PS can be activated by several means, such as heat ${ }^{12}$, transition metals ${ }^{14,15}$, to generate $\mathrm{SO}_{4-}^{-} \cdot$. However, some PS based technology, such as PS/ZVA system ${ }^{13}$, PS/UV-A process ${ }^{16}$, have its own drawbacks, such as precise $\mathrm{pH}$ condition, and not eco-friendly, e.g. in the $\mathrm{CuO} / \mathrm{PMS}$ system ${ }^{14}$. On the other hand, sometimes additional complexion agents were required that would increase the activation efficiency, such as PS/Fe(III)/GA system, but sidewise they may also increase the operational cost. Therefore, it is necessary to develop an economical technology that could degrade IPM under a neutral and mild conditions.

Among these activators, transition metal Fe(II) shows high activity to initiate PS decomposition, as it could be injected directly in subsurface that promotes in-situ oxidation ${ }^{24}$. Especially, owning to its merits, e.g. non-toxic, environmental friendly and relatively low cost, Fe(II) is deemed as one of the most promising activators ${ }^{25}$. Zhu et al. established a kinetic model to describe the iohexol degradation in the Fe(II) activated PS system, and they found that the rate constant of iohexol reacting with sulfate radical was $(1.83 \pm 0.10) \times 10^{926}$. Bu et al. proposed a mathematical model on Fe(II)- activated PS oxidation of atrazine (ATZ), and they observed that only small amount of $\cdot \mathrm{OH}$ were produced while $\mathrm{SO}_{4}^{-} \cdot$ attributed a certain level to ATZ degradation in $\mathrm{Fe}(\mathrm{II}) / \mathrm{PS}$ system ${ }^{27}$.

However, to the best of our knowledge, the investigation on IPM degradation by Fe(II)/PS are rarely reported, up to now. In the present study, Fe(II)/PS oxidation was employed to degrade IPM, and the influence of operational condition parameters on the IPM treatment efficiency was examined to obtain the optimized IPM removal condition parameters. Meanwhile, the IPM degradation pathway was also examined computationally. The obtained results will be very useful for IPM degradation and removal in water and wastewater.

\section{Materials and methods}

Experimental setup and design. All chemicals used in this study were analytical grade. Iopamiol hydrate (IPM, 98\%) was purchased from Meilun (China), and sodium persulfate $\left(\mathrm{Na}_{2} \mathrm{~S}_{2} \mathrm{O}_{8}, 99 \%\right)$ was purchased from Aladdin (China). Ferrous sulfate heptahydrate $\left(\mathrm{FeSO}_{4} \cdot 7 \mathrm{H}_{2} \mathrm{O}, 99.0-101.0 \%\right)$ and sodium carbonate anhydrous $\left(\mathrm{Na}_{2} \mathrm{CO}_{3}\right)$ was purchased from XILONG Chemical CO., LTD. China and Tianjin Mao Tai Chemical Reagent 

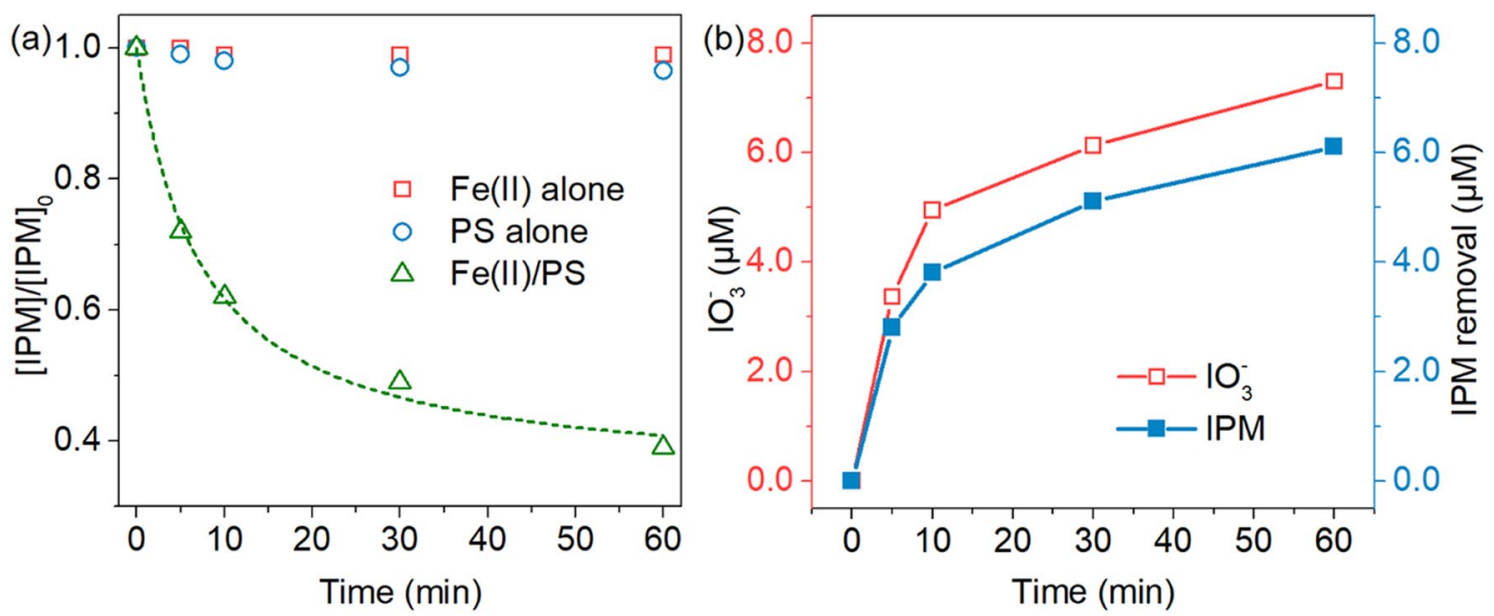

Figure 1. (a) IPM Degradation efficiency by PS alone, Fe(II) alone and Fe(II)/PS, respectively, and (b) the loss of iodine by $\mathrm{Fe}(\mathrm{II}) / \mathrm{PS}$ system under an experimental condition of a initial IPM concentration of $10 \mu \mathrm{M}$, a initial $\mathrm{pH}$ value of 3.0 , at $25^{\circ} \mathrm{C}, \mathrm{Fe}$ (II) concentration of $0.1 \mathrm{mM}$ and a PS concentration of $1 \mathrm{mM}$.

Factory, respectively. Tertiary butyl alcohol (TBA) was purchased from Damao Chemical Reagent Factory, and high performance liquid chromatography (HPLC) grade methanol $(\mathrm{MeOH}, \geq 99.9 \%)$ was supplied by Merck KGaA.

The experiment was performed in a $250 \mathrm{~mL}$ reagent bottle with a working volume of $100 \mathrm{~mL}$, which was installed in an electro-thermal shaking chamber (Shanghai Bluepard Instrument, Co. Ltd., China). During the experiment, $10 \mu \mathrm{M}$ IPM was first prepared with distilled water (Shanghai Hitech Instruments Co., LTD, China). Pre-determined amount of ferrous sulfate solution was added to the reagent bottle. The initial $\mathrm{pH}$ was adjusted with $0.1 \mathrm{M}$ sulfate acid and $0.1 \mathrm{M}$ sodium hydroxide solution, and its temperature was kept at a constant value throughout the reaction. Afterwards, a certain amount of PS $(0.1 \mathrm{M})$ was added. With the progression of reaction, $0.5 \mathrm{~mL}$ mixture in the bottle was accurately sampled at selected time intervals $(0,5,10,30$ and $60 \mathrm{~min})$. Afterwards, the reaction was quenched intermediately by using sufficient volume of methanol, which is an effective scavenger to quench $\mathrm{SO}_{4}^{-}$. and $\cdot \mathrm{OH}$ to stop oxidation reactions. Besides, Iodide $\left(\left(\mathrm{I}^{-}\right)\right.$and iodate $\left(\mathrm{IO}_{3}^{-}\right)$ were analyzed after treatment.

The effect of Fe(II) activated PS oxidation process parameters on IPM degradation was investigated by comparison with a blank experiment. Three parallel experiments were carried out, respectively, by adding $1 \mathrm{mM}$ PS, $0.1 \mathrm{mM} \mathrm{Fe}(\mathrm{II})$, and $\mathrm{Fe}(\mathrm{II}) / \mathrm{PS}$, after that all of them were added and reacted at a $\mathrm{pH}$ of 3 at $25^{\circ} \mathrm{C}$.

Analytical procedures. The concentration of IPM in the solution was determined with an Alliance 2695 Series high-performance liquid chromatography (HPLC) system equipped with a C18 column $(5 \mu \mathrm{m}$, $4.6 \times 20 \mathrm{~mm}$ ) at a UV wavelength of $242 \mathrm{~nm}$. The column temperature was maintained at $35^{\circ} \mathrm{C}$, and the mobile phase was a mixture of methanol/water $(60 / 40, \mathrm{v} / \mathrm{v})$ with a flow rate of $1.0 \mathrm{~mL} \mathrm{~min}^{-1}$. The injection volume was kept at $100 \mu \mathrm{L}$. Iodide (I-) and iodate $\left(\mathrm{IO}_{3}^{-}\right)$were determined by ion chromatography (IC, Thermo Dionex ICS-1500). The sample quenched by sodium sulfite were filtered by BOND ELUTE C18 to remove any organic matters, and then were injected into IC equipped with a IonPacAS9-HC column $(250 \mathrm{~mm} \times 4 \mathrm{~mm})$. The mobile

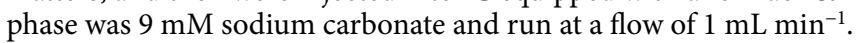

Computational methods. The chemical calculations are performed in the framework of Discrete Fourier Transform (DFT) using Gaussian 09 package according to the previous report ${ }^{28}$. The computational accuracy, feasibility and economical computational time were considered when choosing the computational levels and basis sets. The geometrical parameters were optimized at B3LYP level with a standard of $6-31 G^{\star}$ basis set. Regarding basis set, iodine was defined to fifth cycle element, making the calculations computationally intensive. The use of relativistic effective core potentials is necessary to make the calculations tractable while obtaining accurate theoretical single point energies. Specially, B3LYP /SDD was used for I atom, and the 6-31G* basis set was used for other elements.

\section{Results and discussion}

IPM degradation by Fe(II)/PS oxidation. The degradation efficiency of IPM by Fe(II), PS and Fe(II)/ PS process, was carried out, and it was observed that IPM could be degrade with an obviously higher rate by $\mathrm{Fe}(\mathrm{II}) / \mathrm{PS}$ system, in contrast to Fe(II) or PS (Fig. 1a). As one kind of recalcitrant contaminant, IPM cannot be effectively degraded by sole PS or sole Fe(II), because both of them had a low oxidation ability without activation, and no more than 5\% IPM was found to be removed. On the other hand, a rapid degradation of IPM in the combined system of Fe(II) and PS (Fe(II)/PS) was clearly observed, during which over 60\% IPM could be degraded. These results revealed the effectiveness of Fe(II)/PS system for the removal of IPM in water. The IPM degradation profile by $\mathrm{Fe}(\mathrm{II}) / \mathrm{PS}$ system included apparently two stages, i.e. a fast IPM concentration decreasing 
stage followed by a slow rate, which could be well described by a model accounted for the two distinct kinetic regimes (Eq. 1) $)^{29,30}$ with $\mathrm{R}^{2}$ of 0.994 , as follow:

$$
\frac{\mathrm{C}}{\mathrm{C}_{0}}=1-\frac{\mathrm{t}}{\rho+\sigma t}
$$

where $\mathrm{C}$ and $\mathrm{C}_{0}$ is the substrate concentration at time $\mathrm{t}$ and 0 , respectively. $\rho$ and $\sigma$ are characteristic kinetic constant, while $1 / \rho$ corresponds to the initial reaction rate (i.e. at $t=0$ ), and $1 / \sigma$ corresponds to the maximum conversion rate that can be achieved at the end of the reaction. The first sharp IPM degradation was probably due to $\mathrm{Fe}(\mathrm{II})$, activating a large amount of radicals to oxidize IPM with a high efficiency (Eq. 2). Afterwards, the slow IPM degradation rate might be related with the low radical concentrations after the Fe(II) activation ${ }^{31}$. As shown in Eqs. 3-5, the co-existence of $\mathrm{Fe}(\mathrm{II})$ and $\mathrm{O}_{2}$ can lead to the generation of $\cdot \mathrm{OH}$, which could oxidize organics effectively ${ }^{32}$. Meanwhile, the presence of $\mathrm{O}_{2}$ in this system should not be ignored.

$$
\begin{gathered}
\mathrm{Fe}^{2+}+\mathrm{S}_{2} \mathrm{O}_{8}^{2-} \rightarrow \mathrm{Fe}^{3+}+\mathrm{SO}_{4}^{-}+\mathrm{SO}_{4}^{2-} \\
\mathrm{Fe}^{2+}+\mathrm{O}_{2} \rightarrow \mathrm{Fe}^{3+}+\mathrm{O}_{2}^{-}(\mathrm{pH}<7) \\
\mathrm{Fe}^{2+}+\mathrm{O}_{2}^{-}+2 \mathrm{H}^{+} \rightarrow \mathrm{Fe}^{3+}+\mathrm{H}_{2} \mathrm{O}_{2} \\
\mathrm{Fe}^{2+}+\mathrm{H}_{2} \mathrm{O}_{2} \rightarrow \mathrm{Fe}^{3+}+\cdot \mathrm{OH}+\mathrm{OH}^{-}
\end{gathered}
$$

Within the IMP degradation in $\mathrm{Fe}(\mathrm{II}) / \mathrm{PS}$ system, the concentration of the produced products i.e. iodate $\left(\mathrm{IO}_{3}^{-}\right)$ and iodide $\left(\mathrm{I}^{-}\right)$were simultaneously determined (Fig. 1b), which was consistent with the IPM removal profiles. $\mathrm{IO}_{3}{ }^{-}$concentration in the bulk displayed a significant increasing trend during the reaction, while only a few amount of $\mathrm{I}^{-}$was detected. Because of the quick oxidation of $\mathrm{I}^{-}$into $\mathrm{IO}_{3}{ }^{-}$(Fig. 1b), the $\mathrm{IO}_{3}{ }^{-}$concentration in the bulk increased gradually from 0 to $7.3 \mu \mathrm{M}$, along with the continuous decreasing of IPM concentration, which indicates the occurrence of deiodination.

Optimization of reaction condition parameters in Fe(II)/PS system. Effects of initial PS and $\mathrm{Fe}(\mathrm{II}) /$ PS mole ratio. The effect of initial PS concentration $(0.01,0.05,0.1,0.5,1.0 \mathrm{mM}$ and $2.0 \mathrm{mM})$ on IPM degradation efficiency was carried out under a fixed $\mathrm{Fe}(\mathrm{II}) / \mathrm{PS}$ ratio, with initial $\mathrm{pH}$ of 3.0 at $25^{\circ} \mathrm{C}$. As the concentration of PS was increased from $0.01 \mathrm{mM}$ to $1 \mathrm{mM}$, the IPM initial reaction rate was also increased from $0.0055 \mathrm{~min}^{-1}$ to $0.0903 \mathrm{~min}^{-1}$ (Fig. 2a), which was corresponded to the increased concentration of $\mathrm{IO}_{3}{ }^{-}$from $1.3 \mu \mathrm{M}$ to $7.32 \mu \mathrm{M}$ (Fig. 2b). However, with further increased concentration of PS over $2 \mathrm{mM}$ resulted in a slight improvent of degradation rate constant, as well as a similar trend was observed in the profile of the change of $\mathrm{IO}_{3}{ }^{-}$concentration. The reason for this phenomenon might be due to the excess of PS which can acts as a scavenger of oxidative radicals in $\mathrm{Fe}(\mathrm{II}) / \mathrm{PS}$ system, as described in Eq. $6^{33,34}$.

$$
\mathrm{S}_{2} \mathrm{O}_{8}^{2-}+\mathrm{SO}_{4}^{-} \rightarrow \mathrm{SO}_{4}^{2-}+\mathrm{S}_{2} \mathrm{O}_{8}^{-} \quad k=5.5 \times 10^{5} \mathrm{~mol} \mathrm{~L}^{-1}
$$

In $\mathrm{Fe}(\mathrm{II}) / \mathrm{PS}$ system, $\mathrm{Fe}(\mathrm{II})$ plays a role of an activator for the activation of PS to generate sulfate radicals, which is an important factor that controlled the overall oxidizing ability ${ }^{35}$. Under a constant PS dosage of $1 \mathrm{mM}$, as showed in Fig. 2c, the rate constant for degrading IPM was improved significantly, when the initial Fe(II)/ PS mole ratio increased from $1 / 50$ to $2 / 1$. The generated $\mathrm{IO}_{3}{ }^{-}$concentration was positively correlated with the $\mathrm{Fe}(\mathrm{II}) / \mathrm{PS}$ mole ratios, which reached to the maximum of $8.54 \mu \mathrm{M}$ when the $\mathrm{Fe}(\mathrm{II}) / \mathrm{PS}$ mole ratio increased to $1 / 10$ (Fig. 2d). However, this $\mathrm{IO}_{3}{ }^{-}$concentration began to decline once the $\mathrm{Fe}(\mathrm{II}) / \mathrm{PS}$ mole ratio increased up to $2 / 1$, which revealed the presence of extra excessive $\mathrm{Fe}(\mathrm{II})$ preferentially reacted with $\mathrm{SO}_{4}{ }^{-} \cdot$ via Eq. 7 . Once the $\mathrm{SO}_{4}^{-}$. reached to a high concentration, it would be self-quenched (Eq. 8) ${ }^{36}$, to cause a decrease in the removal efficiency of IPM (Fig. 2d).

$$
\begin{gathered}
\mathrm{Fe}^{2+}+\mathrm{SO}_{4}^{-} \rightarrow+\mathrm{Fe}^{3+}+\mathrm{SO}_{4}^{2-} \quad \mathrm{k}=4.6 \times 10^{9} \mathrm{~mol} \mathrm{~L}^{-1} \\
\mathrm{SO}_{4}^{-}+\mathrm{SO}_{4}^{-} \rightarrow \mathrm{S}_{2} \mathrm{O}_{8}^{2-} \mathrm{k}=8.9 \times 10^{8} \mathrm{~mol} \mathrm{~L}^{-1}
\end{gathered}
$$

Effects of initial $\mathrm{pH}$ and reaction temperature. In all Fe based AOPs, $\mathrm{pH}$ is an important factor affecting the effectiveness of activation of oxidants by $\mathrm{Fe}(\mathrm{II})$ and/or $\mathrm{Fe}(\mathrm{III})^{37}$. Herein, the IPM degradation rate by activated PS was investigated at $\mathrm{pH} 3.0,5.0,7.0,9.0$ and 11.0, respectively, by comparing its resulted IPM degradation efficiency and $\mathrm{IO}_{3}^{-}$generation (Fig. 3). It was observed that the IPM initial reaction rate reached the maximum of $0.0903 \mathrm{~min}^{-1}$ with the initial $\mathrm{pH}$ of 3.0. With the increased $\mathrm{pH}$ value from 3.0 to 11.0 , the rate constant decreased gradually from $0.0903 \mathrm{~min}^{-1}$ to $0.0493 \mathrm{~min}^{-1}$, which was corresponds to the reduction of $\mathrm{IO}_{3}^{-}$from $7.32 \mu \mathrm{M}$ $(\mathrm{pH}=3.0)$ to $3.89 \mu \mathrm{M}(\mathrm{pH}=11.0)$ (Fig. 3a,b). It has been reported that $\mathrm{PS}$ is easily decomposed to produce $\mathrm{SO}_{4}{ }^{2-}$ in an alkaline solution. As shown in Eq. 9 , OH would be generated whose oxidation-reduction potential is lower than $\mathrm{SO}_{4}{ }^{-38}$. However, sulfate and hydroxyl radicals were slightly influenced by the variation of the initial $\mathrm{pH}^{38,39}$. Hence, the main reason was the formation of an $\mathrm{Fe}^{2+}$ complex at $\mathrm{pH}>4.0$ that would be expected to hinder the 

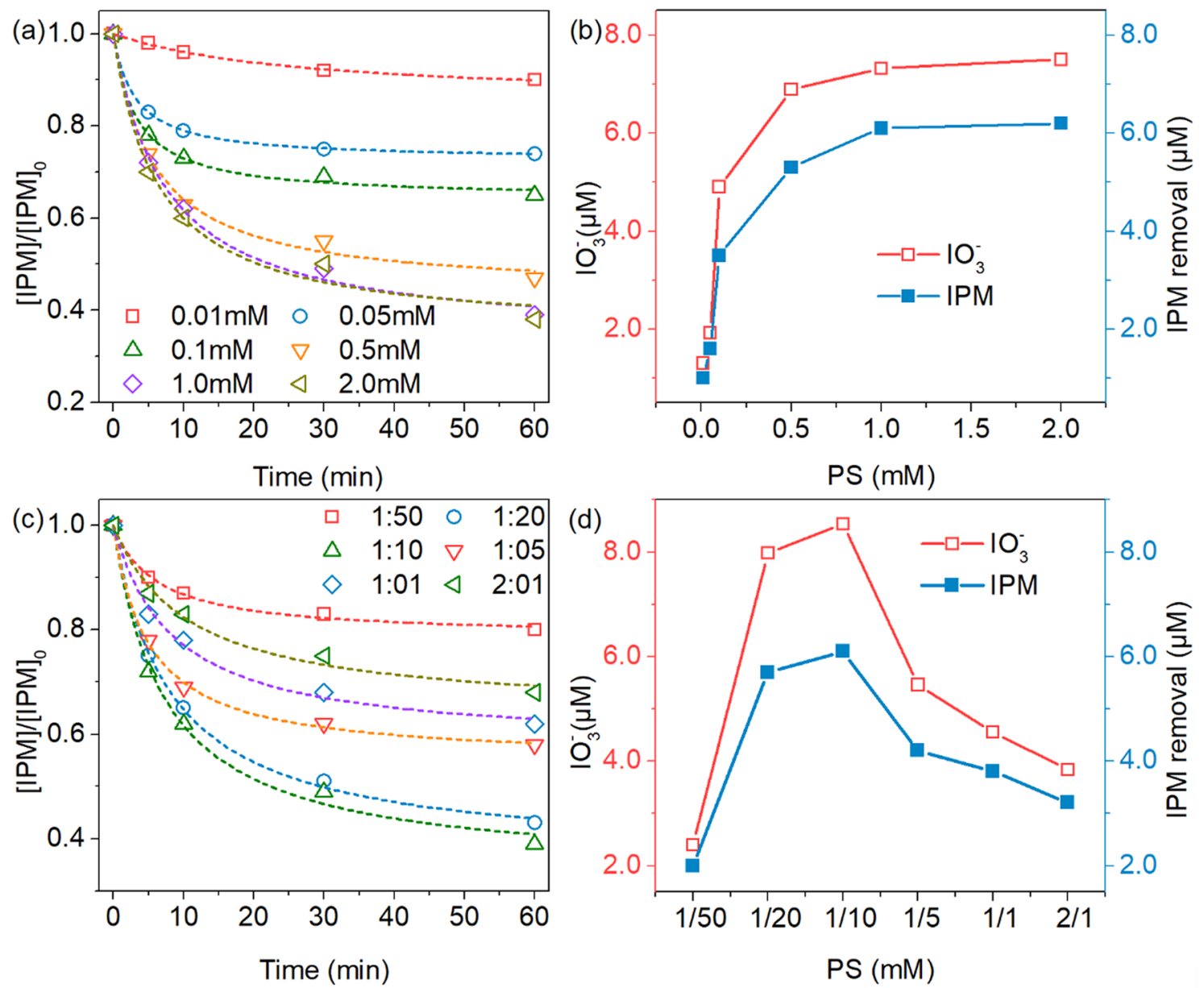

Figure 2. (a) Effect of PS concentration on IPM degradation efficiency, (b) the iodine amount that was removed, under an experimental condition of initial IPM concentration of $10 \mu \mathrm{M}$, a initial $\mathrm{pH}$ value of 3.0, at $25^{\circ} \mathrm{C}$ and a $\mathrm{Fe}(\mathrm{II}) / \mathrm{PS}$ of $1: 10$, (c) Effect of $\mathrm{Fe}(\mathrm{II}) / \mathrm{PS}$ mole ratio on IPM degradation efficiency and (d) the iodine amount that was removed, under an experiment condition of a initial IPM concentration of $10 \mu \mathrm{M}$, a initial $\mathrm{pH}$ value of 3.0 , at $25^{\circ} \mathrm{C}$ and a PS concentration of $1 \mathrm{mM}$.

reaction of $\mathrm{Fe}^{2+}$ with $\mathrm{PS}^{39}$ Hence, the oxidizing ability of the system was decreased, corresponding to a low IPM removal efficiency.

$$
\mathrm{SO}_{4}^{-}+\mathrm{OH}^{-} \rightarrow \cdot \mathrm{OH}+\mathrm{SO}_{4}^{2-}
$$

Besides, the variation of $\mathrm{pH}$ during the reaction was shown in Fig. S1, which displayed a slightly decreasing trend during IPM degradation reaction when the initial $\mathrm{pH}$ was 3.0. The $\mathrm{pH}$ level dropped significantly at the very beginning stage of the reaction, and then remained at a stable level after $5 \mathrm{~min}$ reaction, when the initial $\mathrm{pH}$ was kept above 3.0. This decreasing $\mathrm{pH}$ trend with the IPM degradation might be related closely to the continuous production of $\mathrm{H}^{+}$in the reaction (Eq. 10$)^{40}$.

$$
\mathrm{SO}_{4}^{-}+\mathrm{H}_{2} \mathrm{O} \rightarrow \cdot \mathrm{OH}+\mathrm{H}^{+}+\mathrm{SO}_{4}^{2-}
$$

The impact of reaction temperature, i.e. $25,30,40$ and $45^{\circ} \mathrm{C}$, on IPM degradation rate and subsequent formation of $\mathrm{IO}_{3}{ }^{-}$was also evaluated, under a PS dose of $1 \mathrm{mM}$, an $\mathrm{n}(\mathrm{Fe}(\mathrm{II})) / \mathrm{n}(\mathrm{PS})$ ratio of $1: 10$ and an initial $\mathrm{pH}$ of 3.0. As shown in Fig. 3c, the IPM initial reaction rate was increased from $0.0903 \mathrm{~min}^{-1}$ to $0.1266 \mathrm{~min}^{-1}$, when the temperature increased from 25 to $45^{\circ} \mathrm{C}$, during which the generated $\mathrm{IO}_{3}^{-}$(Fig. $3 \mathrm{~d}$ ) increased from 7.32 to $10.27 \mu \mathrm{M}$. An elevated temperature promotes the degradation and deiodination of IPM, which was mainly caused by the generation of more sulfate radicals. At higher temperature condition, PS would be thermally activated to produce more $\mathrm{SO}_{4}{ }^{-} \cdot$. Moreover, the reaction of $\mathrm{Fe}(\mathrm{II})$ to activate $\mathrm{PS}$ is an endothermic reaction, and high reaction temperature is beneficial to this reaction, and thus to enhance the degradation and deiodination rates of IPM.

Moreover, the degradation of IPM in Fe(II)/PS system may be affected by inorganic ions and natural organic matter (NOM). Therefore, further studies on the environmental impacts would be paid more attention in future. For instance, Zhu et. al found that iohexol degradation would be promoted by the low concentration of chloride 

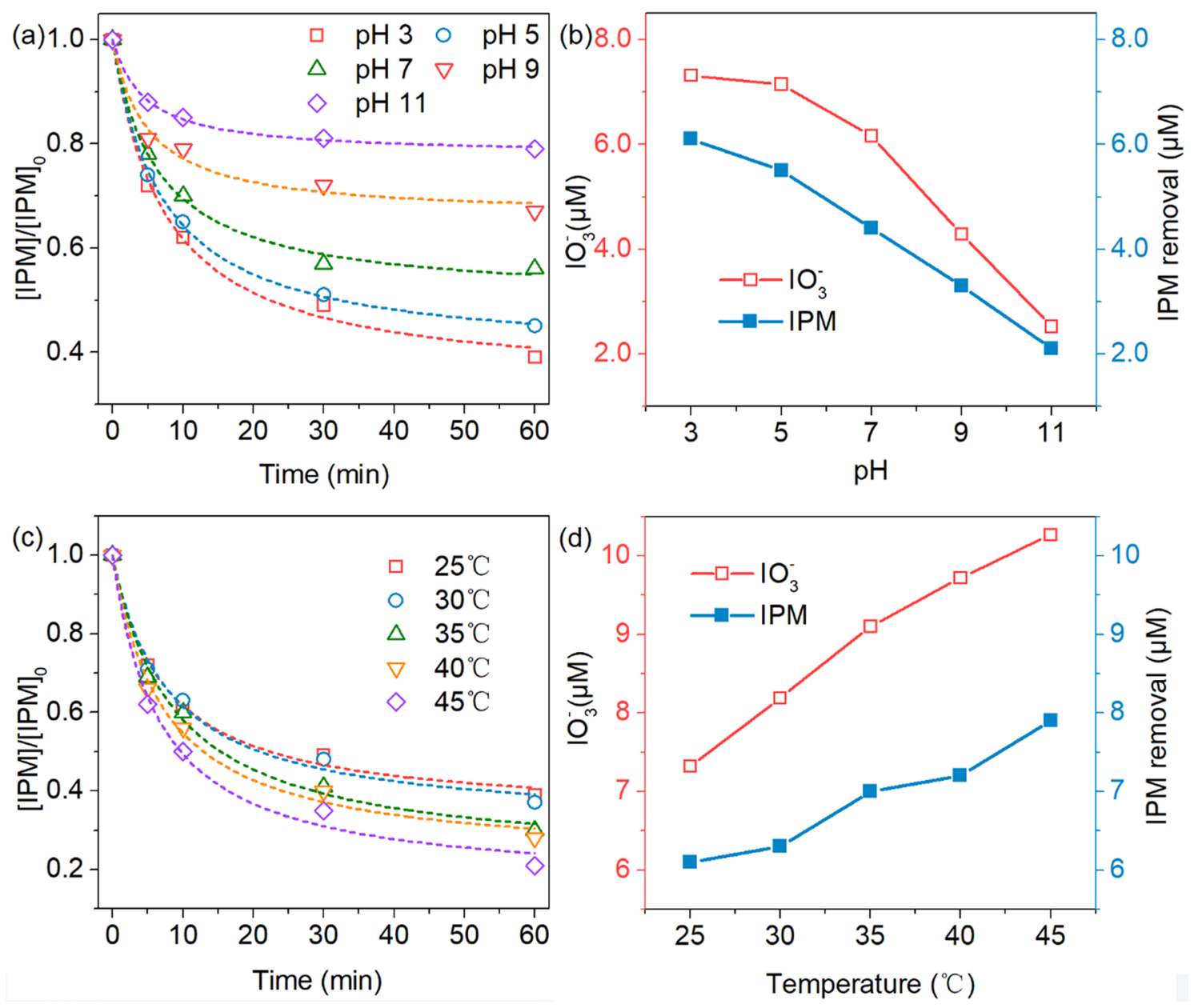

Figure 3. (a) Effect of initial solution $\mathrm{pH}$ on IPM degradation efficiency, (b) the iodine amount that was removed under an experimental condition of an initial IPM concentration of $10 \mu \mathrm{M}$, a PS concentration of $1 \mathrm{mM}$, at $25^{\circ} \mathrm{C}$ and a $\mathrm{Fe}(\mathrm{II}) / \mathrm{PS}$ of $1: 10$, (c) Effect of reaction temperature on IPM degradation efficiency, and (d) the iodine amount that was removed, under an experiment condition of an initial IPM of $10 \mu \mathrm{M}$, a PS of $1 \mathrm{mM}$, a $\mathrm{Fe}(\mathrm{II}) / \mathrm{PS}$ of $1: 10$, and an initial $\mathrm{pH}$ of 3.0 .

ion while inhibited by high concentration, and iohexol degradation was slightly inhibited by $\mathrm{NOM}^{26}$. In another study, Bu et. al found that ATZ degradation performed well at low initial ATZ and NOM concentrations ${ }^{27}$.

Identification of ROS. Radical quenching experiments for the IPM degradation over the 3 samples under a $\mathrm{pH}$ of 3.0 were conducted to explore the catalytic mechanism during $\mathrm{Fe}(\mathrm{II}) / \mathrm{PS}$ system. Generally, it was thought that the active species $\mathrm{SO}_{4}^{-} \cdot$ and $\cdot \mathrm{OH}$ were the possible main active oxidant species in $\mathrm{Fe}(\mathrm{II}) / \mathrm{PS}$ oxidation process ${ }^{27,39}$. During the reaction, methanol $(\mathrm{MeOH})$ was employed as the scavengers of $\mathrm{SO}_{4}{ }^{-} \cdot$ and $\mathrm{OH} \cdot$, while $\mathrm{t}$-butanol (TBA) was applied as the inhibitor of $\cdot \mathrm{OH}^{41,42}$. Figure $4 \mathrm{a}$ demonstrated the quenching experiments of active species under varied dosages of inhibitors $(([\mathrm{MeOH}]$ or $[\mathrm{TBA}]) /[\mathrm{PS}]$ was kept at 0,50 , and 500 , respectively). Without any radical scavenger dosage, the IPM degradation efficiency was around $69 \%$. In comparison, this removal efficiency decreased to $46 \%$ and $55 \%$, when the $\mathrm{MeOH}$ doasges was 50 times and 500 times higher than PS concentration, respectively. Corresponding to the addition of TBA, the degradation efficiency of IPM was declined to $34 \%$ and $41 \%$, respectively, suggesting that the $\cdot \mathrm{OH}$ was the dominant radical in the degradation of IPM.

The EPR spin-trap technique was also carried out to unveil the reactive species in Fe(II)/PS process for IPM degradation, where 5, 5-dimethyl-1-pyrroline-N-oxide (DMPO) was used as a spin-trapping agent to capture $\mathrm{SO}_{4}{ }^{-} \cdot$ and $\cdot \mathrm{OH}$. As depicted in Fig. 4b, there was rather insignificant EPR signals with Fe(II) alone or PS alone, indicating rare absence of $\mathrm{SO}_{4}^{-} \cdot$ and $\cdot \mathrm{OH}$ generation. Upon the PS and $\mathrm{Fe}(\mathrm{II})$ dosage to form $\mathrm{Fe}(\mathrm{II}) / \mathrm{PS}$ oxidation process, four characteristic peaks, including $\mathrm{a}_{\mathrm{N}}=\mathrm{a}_{\mathrm{H}}=14.9 \mathrm{G}$ for DMPO-OH$\cdot$ adducts, and the characteristic peaks $\left(\mathrm{a}_{\mathrm{N}}=13.9 \mathrm{G}, \mathrm{a}_{\mathrm{H}}=10 \mathrm{G}, \mathrm{a}_{\mathrm{H}}=1.48 \mathrm{G}, \mathrm{a}_{\mathrm{H}}=0.78 \mathrm{G}\right)$ for $\mathrm{DMPO}-\mathrm{SO}_{4}{ }^{-} \cdot$ adduct were found in the EPR spectrum, whose intensity ratio was around $1: 2: 2: 1^{43}$. In addition, the DMPO- $\mathrm{SO}_{4}{ }^{-}$. adduct showed weak signals than the $\mathrm{DMPO}-\mathrm{OH} \cdot$ adduct, which were in accordance with the radical trapping experiments. 

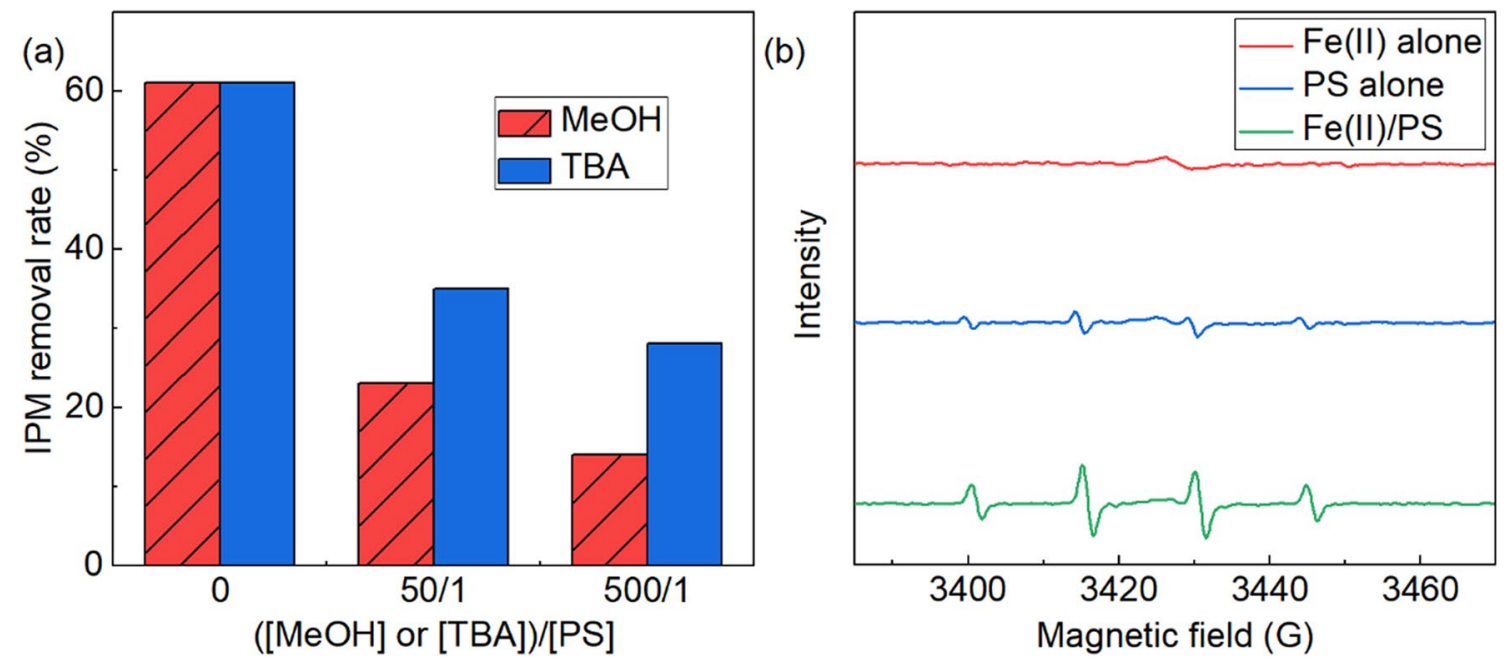

Figure 4. (a) IPM degradation efficiency with different inhibitors, and (b) EPR spectra of DMPO-OH. and $\mathrm{DMPO}-\mathrm{SO}_{4}$.

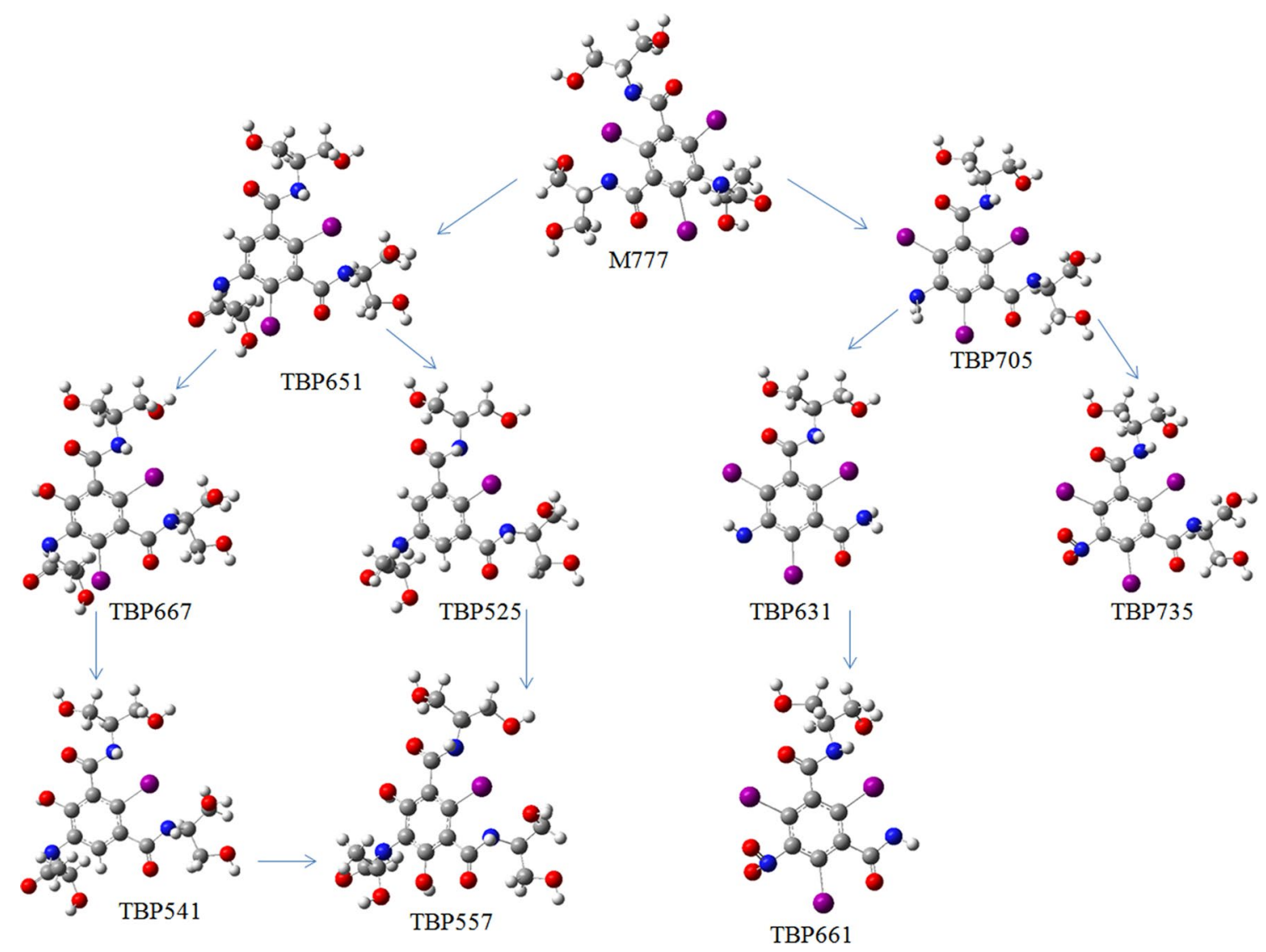

Figure 5. Possible degradation pathways of IPM by Fe(II)/PS system.

IPM degradation products and reaction paths. Based on DFT quantum chemistry calculation, the degradation of IPM products and pathways in Fe(II)/PS system were analyzed. The chemical calculation is mainly based on the DFT model under Gaussian 09 where the calculation method and basis set are set for computer precision and flexibility, and comprehensive consideration of time-consuming calculations.

The main types of IPM and $\cdot \mathrm{OH}$ radical reactions are presented in Fig. 5. Accordingly, iodine on the IPM phenyl ring would firstly be removed to produce TP651 (Eq. 11). Secondly, at this position, a hydrogen atom would be replaced by a hydroxyl group to induce hydroxylation and to produce TP667 (Eq. 12). Afterwards, the iodine at another position on the benzene ring of TP667 was removed to produce TP541 (Eq. 13), and the hydroxylation 
reaction occurred at the position where iodine was removed by TP541, where one hydrogen atom could be replaced by a hydroxyl group to form TP557 (Eq. 14). On the other hand, TP651 may also directly be removed iodine to produce TP525 (Eq. 15), whose benzene ring would then be hydroxylated to remove two iodines, and meanwhile the hydrogen atom could be replaced by a hydroxyl group to produce TP557 (Eq. 16). Therefore, it is reasonable to think that the IPM branch underwent a deacetylation reaction path with the action of $\cdot \mathrm{OH}$.

In addition, there is another possible IPM degradation path, during which the acetyl group would be deacetylated to produce TP705 (Eq. 17). Then, the branch of TP705 would be cleaved under the action of $\cdot \mathrm{OH}$ to produce TP631 (Eq. 18), which afterwards could be oxidized by $\cdot \mathrm{OH}$ to produce TP661 (Eq. 19). Apart from the abovementioned paths, TP705 could also directly undergo amine oxidation path under the oxidation of $\cdot \mathrm{OH}$, to produce TP735 (Eq. 20).<smiles>C[C@H](O)C(=O)Nc1c(I)c(C(=O)NC(CO)CO)c(I)c(C(=O)NC(CO)CO)c1I</smiles><smiles>C[C@@H](O)C(=O)Nc1c(I)c(C(=O)NC(CO)CO)c(I)c(C(=O)NC(CO)CO)c1I</smiles><smiles>Cc1c(NC(=O)[C@H](C)O)c(O)c(C(=O)NC(CO)CO)c(I)c1C(=O)NC(CO)CO</smiles><smiles>C[C@@H](O)C(=O)Nc1cc(C(=O)NC(CO)CO)c(I)c(C(=O)NC(CO)CO)c1O</smiles><smiles>C[C@H](O)C(=O)Nc1c(I)c(C(=O)NC(CO)CO)c(I)c(C(=O)NC(CO)CO)c1I</smiles><smiles>C[C@H](O)C(=O)Nc1cc2c(C(=O)NC(CO)CO)c(I)c(C(=O)NC(CO)CO)c(I)c2c(O)c1NC(=O)[C@H](C)O</smiles> 


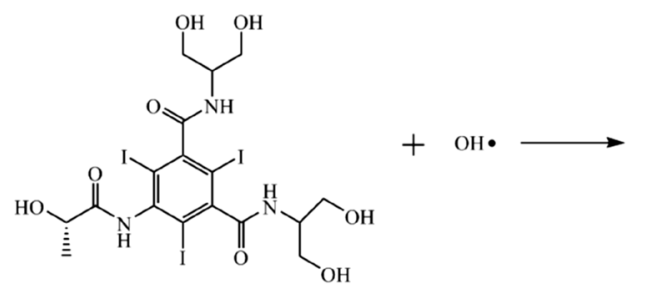

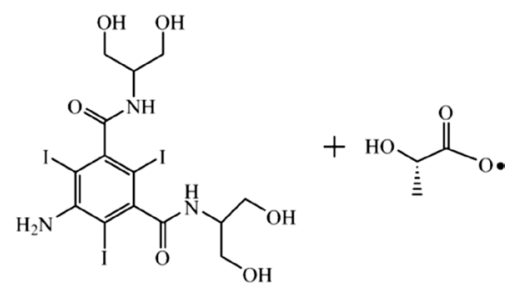<smiles>Nc1c(I)c(C(=O)NC(CO)CO)c(I)c(C(=O)NC(CO)CO)c1I</smiles><smiles>NC(=O)c1c(I)c(N)c(I)c(C(=O)NC(CO)CO)c1I</smiles><smiles>NC(=O)c1c(I)c(N)c(I)c(C(=O)NC(CO)CO)c1I</smiles><smiles>CCCCCCC</smiles><smiles>NC(=O)c1c(I)c(C(=O)NC(CO)CO)c(I)c([N+](=O)[O-])c1I</smiles><smiles>Nc1c(I)c(C(=O)NC(CO)CO)c(I)c(C(=O)NC(CO)CO)c1I</smiles><smiles>CCCC</smiles><smiles>O=C(NC(CO)CO)c1c(I)c(C(=O)NC(CO)CO)c(I)c([N+](=O)[O-])c1I</smiles>

\section{Conclusion}

IPM, a typical non-ionic ICM compound, was effectively degraded by using sulfate activated PS oxidation (Fe(II)/ PS) system. The effect of PS concentration, $\mathrm{Fe}(\mathrm{II}) / \mathrm{PS}$ mole ratio, initial $\mathrm{pH}$, and operation temperature, on the IPM removal rate, as well as on the loss of iodine, were comprehensively investigated. The optimum degradation condition parameters were as follows: the $10 \mathrm{mmol} \mathrm{L}^{-1} \mathrm{PS}$ concentration, $1: 10 \mathrm{n}(\mathrm{Fe}(\mathrm{II})) / \mathrm{n}(\mathrm{PS}), 3.0 \mathrm{pH}$ and $45^{\circ} \mathrm{C}$ temperature. The PS concentration increased from 10 to $1 \mathrm{mM}$ which could enhance the IPM degradation and deiodination rates. Compared to alkaline conditions, acidic and neutral conditions were favorable for IPM degradation. The combination of $\mathrm{SO}_{4}^{-} \cdot$ and $\cdot \mathrm{OH}$ contributed to the effectiveness of IPM removal. Through DFT quantum chemical calculations, the possible reaction path of IPM degradation was mainly included hydroxylation, deiodination, deacetylation, and amine oxidation, and finally all of the iodine removed was transformed into $\mathrm{IO}_{3}^{-}$.

Herein, this IPM initiate reaction rate of $0.1266 \mathrm{~min}^{-1}$ is quite higher in contrast to those listed in Table 1, under the relatively mild reaction condition. Fe(II) /PS system for IPM degradation in this study showed an excellent performance, compared to anaerobic process, PS/Fe(III) or UV system. Meanwhile, Fe(II)/PS system had a high economic feasibility, as it could degrade IPM without any additional complexion agents or expensive catalysts dosage, such as gallic acid, $\mathrm{Fe}(\mathrm{VI})$ or zero-valent aluminum. Moreover, $\mathrm{Fe}(\mathrm{II}) / \mathrm{PS}$ system possessed the advantage of sustainable, which did not need any hazardous materials and could not result in any secondary pollution. Therefore, it is reasonable to realize that, the PS/Fe(II) system reported in this study provided a sustainable approach for the practical treatment of refractory pollutants, and further studies should be carried out to evaluate its environmental impacts and stability.

\section{Data availability}

All data or models generated or used during the study are available from the corresponding author by request. 


\section{References}

1. Pérez, S. \& Barceló, D. Fate and occurrence of X-ray contrast media in the environment. Anal. Bioanal. Chem. 387, 1235-1246 (2007).

2. Jeong, C. H. et al. The impact of iodinated X-ray contrast agents on formation and toxicity of disinfection by-products in drinking water. J. Environ. Sci. 58, 173-182 (2017).

3. Plewa, M. J. et al. Chemical and biological characterization of newly discovered iodoacid drinking water disinfection byproducts. Environ. Sci. Technol. 38, 4713-4722 (2004).

4. Richardson, S. D., Plewa, M. J., Wagner, E. D., Schoeny, R. \& DeMarini, D. M. Occurrence, genotoxicity, and carcinogenicity of regulated and emerging disinfection by-products in drinking water: A review and roadmap for research. Mutation Res./Rev. Mutation Res. 636, 178-242 (2007).

5. Xu, Z., Li, X., Hu, X. \& Yin, D. Distribution and relevance of iodinated X-ray contrast media and iodinated trihalomethanes in an aquatic environment. Chemosphere 184, 253-260 (2017).

6. Simazaki, D. et al. Occurrence of selected pharmaceuticals at drinking water purification plants in Japan and implications for human health. Water Res. 76, 187-200 (2015).

7. Duirk, S. E. et al. Formation of toxic iodinated disinfection by-products from compounds used in medical imaging. Environ. Sci. Technol. 45, 6845-6854 (2011).

8. Dong, H. et al. Deiodination of iopamidol by zero valent iron (ZVI) enhances formation of iodinated disinfection by-products during chloramination. Water Res. 129, 319-326 (2018).

9. Anirban, D. et al. Solar photocatalytic degradation of trace organic pollutants in water by $\operatorname{Bi}(0)$-doped Bismuth oxyhalide thin films. ACS Omega 3, 10858-10865 (2018).

10. Kong, X., Jiang, J., Ma, J., Yang, Y. \& Pang, S. Comparative investigation of X-ray contrast medium degradation by UV/chlorine and UV/H2O2. Chemosphere 193, 655-663 (2018).

11. Redeker, M., Wick, A., Meermann, B. \& Ternes, T. A. Anaerobic transformation of the iodinated X-ray contrast medium iopromide, its aerobic transformation products, and transfer to further iodinated X-ray contrast media. Environ. Sci. Technol. 52, 8309-8320 (2018).

12. Pan, X., Yan, L., Qu, R. \& Wang, Z. Degradation of the UV-filter benzophenone-3 in aqueous solution using persulfate activated by heat, metal ions and light. Chemosphere 196, 95-104 (2018).

13. Arslan-Alaton, I., Olmez-Hanci, T., Korkmaz, G. \& Sahin, C. Removal of iopamidol, an iodinated X-ray contrast medium, by zero-valent aluminum-activated $\mathrm{H}_{2} \mathrm{O}_{2}$ and $\mathrm{S}_{2} \mathrm{O}_{8}{ }^{2-}$. Chem. Eng. J. 318, 64-75 (2017).

14. Hu, J., Dong, H., Qu, J. \& Qiang, Z. Enhanced degradation of iopamidol by peroxymonosulfate catalyzed by two pipe corrosion products $\left(\mathrm{CuO}\right.$ and $\left.\delta-\mathrm{MnO}_{2}\right)$. Water Res. 112, 1-8 (2017).

15. Sarro, M. et al. ZnO-based materials and enzymes hybrid systems as highly efficient catalysts for recalcitrant pollutants abatement. Chem. Eng. J. 334, 2530-2538 (2018).

16. Arslan-Alaton, I., Kolba, O. \& Olmez-Hanci, T. Removal of an X-ray contrast chemical from tertiary treated wastewater: Investigation of persulfate-mediated photochemical treatment systems. Catal. Today 313, 134-141 (2018).

17. Dong, H. et al. Oxidation of iopamidol with ferrate (Fe(VI)): Kinetics and formation of toxic iodinated disinfection by-products. Water Res. 130, 200-207 (2018).

18. Tian, F.-X. et al. Chlor(am)ination of iopamidol: kinetics, pathways and disinfection by-products formation. Chemosphere 184, 489-497 (2017).

19. Fabbri, D. et al. Iodinated X-ray contrast agents: Photoinduced transformation and monitoring in surface water. Sci. Total Environ. 572, 340-351 (2016).

20. Dong, H., Qiang, Z., Hu, J. \& Sans, C. Accelerated degradation of iopamidol in iron activated persulfate systems: Roles of complexing agents. Chem. Eng. J. 316, 288-295 (2017)

21. Olmez-Hanci, T. et al. Enhanced degradation of micropollutants by zero-valent aluminum activated persulfate: assessment of toxicity and genotoxic activity. Water Sci. Technol. 76, 3195-3204 (2017).

22. Paganini, M. C. et al. Beyond $\mathrm{TiO}_{2}$ : cerium-doped zinc oxide as a new photocatalyst for the photodegradation of persistent pollutants. ChemistrySelect 1, 3377-3383 (2016).

23. Schneider, A.-L. et al. Electrochemical oxidation of iodinated X-ray contrast media by boron-doped diamond electrodes. $d w t$ (91, 268-272 (2017).

24. Liu, H. et al. Oxidation of benzene by persulfate in the presence of Fe(III)- and Mn(IV)-containing oxides: stoichiometric efficiency and transformation products. Environ. Sci. Technol. 50, 890-898 (2016).

25. Rastogi, A., Al-Abed, S. R. \& Dionysiou, D. D. Effect of inorganic, synthetic and naturally occurring chelating agents on Fe(II) mediated advanced oxidation of chlorophenols. Water Res. 43, 684-694 (2009).

26. Zhu, J.-P. et al. Modelling of iohexol degradation in a Fe(II)-activated persulfate system. Chem. Eng. J. 367, 86-93 (2019).

27. Bu, L., Shi, Z. \& Zhou, S. Modeling of Fe(II)-activated persulfate oxidation using atrazine as a target contaminant. Sep. Purif. Technol. 169, 59-65 (2016)

28. Shang, W. et al. Degradation of diatrizoate in water by Fe(II)-activated persulfate oxidation. Chem. Eng. J. 361, 1333-1344 (2019).

29. Frontistis, Z. et al. Fast degradation of estrogen hormones in environmental matrices by photo-Fenton oxidation under simulated solar radiation. Chem. Eng. J. 178, 175-182 (2011).

30. Chan, K. H. \& Chu, W. Modeling the reaction kinetics of Fenton's process on the removal of atrazine. Chemosphere 51, 305-311 (2003).

31. Rodriguez, S., Vasquez, L., Costa, D., Romero, A. \& Santos, A. Oxidation of Orange G by persulfate activated by Fe(II), Fe(III) and zero valent iron (ZVI). Chemosphere 101, 86-92 (2014).

32. Ding, W. et al. Co-oxidation of $\mathrm{As}(\mathrm{III})$ and $\mathrm{Fe}(\mathrm{II})$ by oxygen through complexation between $\mathrm{As}(\mathrm{III})$ and $\mathrm{Fe}(\mathrm{II}) / \mathrm{Fe}(\mathrm{III}) \mathrm{species}$. Water Res. 143, 599-607 (2018).

33. Hori, H. et al. Efficient decomposition of environmentally persistent perfluorocarboxylic acids by use of persulfate as a photochemical oxidant. Environ. Sci. Technol. 39, 2383-2388 (2005).

34. Gao, Y., Gao, N., Deng, Y., Yang, Y. \& Ma, Y. Ultraviolet (UV) light-activated persulfate oxidation of sulfamethazine in water. Chem. Eng. J. 195-196, 248-253 (2012).

35. Rao, Y. F., Qu, L., Yang, H. \& Chu, W. Degradation of carbamazepine by Fe(II)-activated persulfate process. J. Hazard. Mater. 268, 23-32 (2014).

36. Xu, X.-R. \& Li, X.-Z. Degradation of azo dye Orange G in aqueous solutions by persulfate with ferrous ion. Sep. Purif. Technol. 72, 105-111 (2010).

37. Jiang, C., Pang, S., Ouyang, F., Ma, J. \& Jiang, J. A new insight into Fenton and Fenton-like processes for water treatment. J. Hazard. Mater. 174, 813-817 (2010).

38. Xie, P. et al. Removal of 2-MIB and geosmin using UV/persulfate: contributions of hydroxyl and sulfate radicals. Water Res. 69, 223-233 (2015).

39. Wang, S. et al. Removal of acetaminophen in the Fe2+/persulfate system: kinetic model and degradation pathways. Chem. Eng. J. 358, 1091-1100 (2019). 
40. Zhou, L. et al. Ferrous-activated persulfate oxidation of arsenic(III) and diuron in aquatic system. J. Hazard. Mater. 263, 422-430 (2013).

41. Anipsitakis, G. P. \& Dionysiou, D. D. Radical generation by the interaction of transition metals with common oxidants. Environ. Sci. Technol. 38, 3705-3712 (2004).

42. Antoniou, M. G., de la Cruz, A. A. \& Dionysiou, D. D. Degradation of microcystin-LR using sulfate radicals generated through photolysis, thermolysis and e- transfer mechanisms. Appl. Catal. B 96, 290-298 (2010).

43. Chen, L. et al. strong enhancement on fenton oxidation by addition of hydroxylamine to accelerate the ferric and ferrous iron cycles. Environ. Sci. Technol. 45, 3925-3930 (2011).

\section{Acknowledgement}

This research was supported by the grant Project supported by Guangdong Natural Science Foundation No. 2017A030313285, from the Shenzhen Science and Technology Funding Project (Grant Number JSGG2017041401900541), from National Natural Science Foundation of China (Grant Numbers 51678183, 51408149).

\section{Author contributions}

Z.D. designed the research concept; C.J. collected data; M.L. performed the DFT computations; G.C. analyzed output data, prepared all figures, and wrote the main manuscript text; F.S. reviewed and edited the manuscript; B.B. edited the manuscript; Z.D. and F.S. supervised the project.

\section{Competing interests}

The authors declare no competing interests.

\section{Additional information}

Supplementary Information The online version contains supplementary material available athttps://doi. org/10.1038/s41598-020-78468-y.

Correspondence and requests for materials should be addressed to F.S.

Reprints and permissions information is available at www.nature.com/reprints.

Publisher's note Springer Nature remains neutral with regard to jurisdictional claims in published maps and institutional affiliations.

(c) (i) Open Access This article is licensed under a Creative Commons Attribution 4.0 International License, which permits use, sharing, adaptation, distribution and reproduction in any medium or format, as long as you give appropriate credit to the original author(s) and the source, provide a link to the Creative Commons licence, and indicate if changes were made. The images or other third party material in this article are included in the article's Creative Commons licence, unless indicated otherwise in a credit line to the material. If material is not included in the article's Creative Commons licence and your intended use is not permitted by statutory regulation or exceeds the permitted use, you will need to obtain permission directly from the copyright holder. To view a copy of this licence, visit http://creativecommons.org/licenses/by/4.0/.

(c) The Author(s) 2020 